\title{
'Fresh variants and formulations frozen': Structural features of commercial signs in Oman
}

\author{
Louisa Buckingham Bilkent University
}

This study analyses structural features of English on commercial signs on shop frontages throughout Oman. The study identifies frequently used structural features which appear to be undergoing a process of nativization (Schneider 2003) within the context of this text type. These include word class flexibility, the extensive use of the gerund at the end of noun phrases and the use of multiple verbs to itemize discrete activities. In some cases, features appear to serve the functions of economizing, or heightening the prominence or degree of explicitness of content; in other cases, structural features revealed the influence of Arabic. Limited evidence was also found for features previously identified in other lingua franca contexts such as the genitive structure with inanimate nouns and plural uncountable nouns.

Keywords: English as a lingua franca, commercial signs, advertising, language contact, Arabic, the Gulf

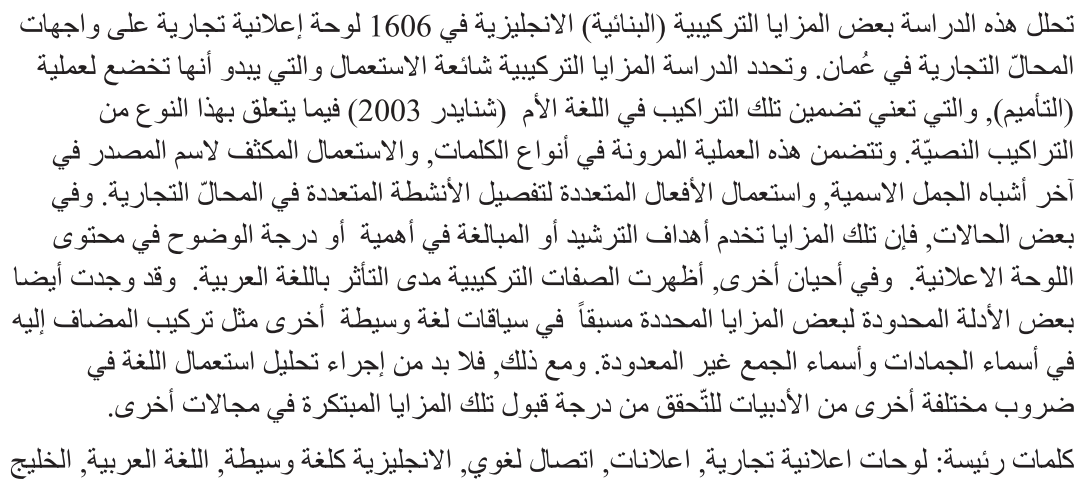

\section{Introduction}

The member states of the Gulf Cooperation Council ${ }^{1}$ (GCC) constitute rich territory for the study of languages in contact. Not only are autochthonous 
languages numerous (Peterson 2004), but the influx of expatriate workers since the discovery of oil has resulted in the growth of vibrant, multilingual communities with their own social networks, educational institutions and consumer preferences. The proportion of expatriates to nationals varies considerably; for instance, in countries such as Qatar and the United Arab Emirates (UAE), expatriate workers vastly outnumber nationals, while in Oman they constitute around $44 \%$ of the population (EIU 2013). ${ }^{2}$ In all GCC countries, however, English has surfaced as the principal (but not sole) lingua franca in the workplace between expatriate communities and nationals and between the multifarious nationalities which comprise expatriate communities. Little has been done to date in the description and analysis of English in contact with Arabic and Asian languages in GCC countries; Boyle's (2011) exploratory corpus study of English in the media in the UAE constitutes one of the first to investigate systematically the use of English as a lingua franca (ELF) in this region using corpus data.

This study presents an analysis of the use of English as a lingua franca on commercial signs above shops in Oman, from the perspective of Schneider's (2003) model of the development of post-colonial Englishes. Commercial signs in Oman are required to be bilingual (English/Arabic) national-wide. ${ }^{3}$ The information provided on the sign, such as the degree of detail, may not always be identical in the two languages, however. ${ }^{4}$ The provision of information in two languages caters for the country's ethnically and linguistically heterogeneous inhabitants, even when the goods provided are unlikely to be sought by the expatriate community (such as the sale of traditional Omani clothing).

Shop signs are by nature very public displays of language and, as such, are exposed to corrective feedback or conformist pressures. With few exceptions, ${ }^{5}$ the vast majority of stores in Oman constitute a unique retail outlet or service provider; consequently, decisions regarding the phrasing of advertising on the store's signage are taken by the local store proprietors (and subject to approval by the local municipality), rather than at a distant head office. As the commercial success of an enterprise relies on its reception by consumers, it is in its interests to use promotional language on signage that is easily comprehensible and reflects the language use of the targeted community. Innovative language use may not necessarily be widely understood or be commercially effective in a highly multilingual and multi-ethnic context. Signs also offer durable linguistic evidence and may remain in place for many years. Hence, this study sheds light on how English is used within a comparatively conservative linguistic genre to advertise goods and services to the local indigenous and expatriate population. The data for this study come from a corpus of 1,606 commercial shop signs compiled nationwide between 2012 and 2013.

\section{English in Oman}

English is the de facto second official language in Oman after Arabic and is widely used in economic spheres such as the banking and petroleum sectors; 


\section{8 - Louisa Buckingham}

it is also the medium of communication in the tertiary education sector (excepting disciplines such as Arabic language, education and culture). With a steady flow of workers from Western, South Asian and, more recently, Southeast Asian countries, pragmatism is among the reasons behind the adoption of English as the country's second language. As expatriate workers have temporary visas without a clear prospect of permanent residency or citizenship, the opportunity and motivation for most workers to learn Arabic is limited. While other languages such as Hindi, Urdu and Swahili are also used to a more limited extent to facilitate communication between different linguistic communities (Peterson 2004; Valeri 2007), English has become the most widespread and prestigious lingua franca in the region.

English may be spoken in Oman as a first language (whether by functionally monolingual, bilingual or multilingual speakers) or as second language by people with near-native competence, whether they be speakers from outer circle countries (in accordance with the Kachruvian paradigm) with higher levels of formal education or by Omanis from certain privileged social sectors (Holes 2011), while a considerable number speak English as a foreign language, usually those who learnt it as an obligatory subject in educational contexts, or informally in their work environment. The level of English competence among the third group may vary drastically. While many may be functionally highly competent in both work and social contexts (such workers are more likely to be found in the hospitality industry, for example), manual workers (whether in the construction or trade sectors) may have had little exposure to English during their schooling or may indeed have had little formal education.

\section{Conceptualizing English as a lingua franca in the Gulf: Two models}

The Kachruvian terms inner, outer and expanding circles derived from Kachru's (1985) tripartite model, continue to be commonly used in applied linguistics (Yano 2001). In essence, the Kachruvian paradigm represents an attempt to classify countries in terms of their relationship with the English language, determined as a by-product of European imperialism, an "accident of political history" (Bruthiaux 2003: 167). The model's enduring quality is doubtlessly its simplicity and ease of use, but its application inevitably bypasses deeper engagement with sociolinguistic complexities (Canagarajah 1999; Bruthiaux 2003; Pennycook 2003; Schneider 2003; Dewey 2007; Jenkins 2009; Park and Wee 2009). Oman would constitute an expanding circle context in Kachruvian terms, but no analysis of linguistic practices within this nation can afford to ignore the large, fluid populace transplanted from neighbouring inner circle South Asia. Thus, in contexts where the dynamics of globalization have occasioned increasingly transnational communities and the translocation 
of languages and cultural practices, viewing communities or even nationstates as monolithic entities becomes unsustainable.

In contrast, Schneider's (2003) dynamic framework accounts for the varied nature of English use within communities. Basing his model on an analysis of postcolonial contexts, he identifies five potential stages through which the development of English (or potentially any other language originally used as a lingua franca within a territory) may traverse: from the foundation stage to a potential, but seldom, 'differentiation' stage, involving the emergence of a new, codified language variety. ${ }^{6}$ The Schneider model allows for the uneven distribution of English use and competency within a territory, as the model is conceived as a process in which different stages may be found within a country at any one point (Schneider 2003: 244, 272). Thus, for much of the transient expatriate population in Oman with little formal educational background, contact with English may be at the 'foundation' stage, but they will have to operate in a society where English is the de facto second language of key social sectors through which state power is exercised (such as education, state administration and the media). Thus this initial phase co-exists with the more advanced phase of 'exonormative stabilization'. Other large expatriate communities employed in skilled sectors may have been resident in the country for decades or even generations (Peterson 2004); through extensive use of English as a lingua franca or as a second language within their professional lives, the nativization of particular lexicogrammatical features has gradually begun. This third stage embodies a sense of linguistic autonomy; that is, linguistic features that may have previously been the subject of social stigma are now widely employed and perceived as 'normal' or are appropriated by the community as cultural and identity traits.

Though originally conceived to account for language accommodation processes occurring in colonized countries, the model can also be applied in the case of a country such as Oman, which, despite having been a British protectorate in the 1800s, was never a colony (Al-Naqeeb 1990). It would be hard to conceptualize this period as the foundation stage for the introduction of English, however, as British interests were limited to Muscat's role as a trading post, which was administered from British India (Al-Naqeeb 1990: 47). Thus Oman was neither settled by the British and nor was English widely used at this time.

A more realistic foundation stage for English in Oman would be that following the development of the petroleum-based rentier economy after 1950, which brought an influx of expatriate workers (primarily Arab and South Asian), employed throughout almost all economic sectors. English became the channel for work-related communication between different ethnic and linguistic groups, particularly as in later decades political considerations led to a preference for South Asian over Arab workers (Kapiszewski 2006; Willoughby 2006). Some (non-Arab) expatriate workers develop competency in a simplified form of Arabic, termed pidgin Arabic by 


\section{0 - Louisa Buckingham}

Holes (2011); the term lingua franca would also be appropriate if the broader definition of the term is used to include both NS and NNS (Jenkins 2009). Languages used in social and cultural spheres usually remain the native or dominant language or dialect used in the workers' home communities (for instance, Urdu, Pashtu, Hindi, Bengali, Malayalam or Tamil). Schneider (2007) refers to this third community contributing to language contact and change as an 'adstrate community', in the sense that it embodies an additional linguistic community to the superstrate settler or administrative class (represented by the British ${ }^{7}$ ), and the substrate indigenous population, in this case, the Omani Arabs.

Thus, in the case of Oman, the second stage of Schneider's model, the exonormative stabilization phase, is not characterized by a resident community of native speakers providing a stable, prestigious usage model, but rather an orientation towards exogenous norms in the educational sector ${ }^{8}$ concomitant with the accommodation by Omani speakers of English to a transient expatriate community on temporary work visas with greatly varying degrees of English ability. The transformative potential of this language contact environment can be seen insofar as both Hindi and English words become part of the local Arabic spoken dialect, to the extent that non Gulf Arabs may deride the lack of 'linguistic purity' in the Omani Arabic dialect (Holes 2011). Particular words have entered the Omani Arabic spoken dialect such as 'sida' (straight ahead) from Hindi, together with English words from trade sectors such as 'cable', 'light', 'switch', 'screwdriver', reflective of the dominance of certain ethnic or linguistic groups in specific trade sectors (such as car mechanics, electrical appliance repairs, property cleaning and maintenance).

As Boyle (2012) ascertains, Milroy's (2004) social network theory provides a useful lens through which to view the processes of linguistic accommodation and dialect leveling which characterize the innovative use of English during exchanges between the different linguistic groups resident in the Gulf. Accordingly, dense multiplex social networks (such as those existing in a migrant worker's home community) will likely be more bounded to localized linguistic norms and resistant to change than loose uniplex social networks common among migrant communities in the Gulf. In the case of South Asian migrants, not only may English competence vary considerably but so may the particular variety of English used in a migrant's home community. Transplanted to the Gulf, the use of restructuring and accommodation processes employed by different ethnic or linguistic groups when communicating in a lingua franca context leads to a convergence on particular forms that demonstrably facilitate successful communicative outcomes and the suppression of forms that do not.

Using Schneider's dynamic model of language contact as a framework, this paper will explore how English is used in commercial signs as a lingua franca throughout Oman. The study will show that, in addition to displaying traits of simplification, reduction, and analogy, English use within this genre 
has developed innovative forms which appear to have met with acceptance (or be in the process of nativization, according to the third stage of Schneider's model) as appropriate formulations within this domain, and are thus testimony to the transformative capacity (Dewey 2007) of language when used extensively in a relatively stable lingua franca context over an extended period of time. Dewey (2007: 347) posits that, parallel to the diversity and dynamism inherent in language use in lingua franca contexts, identifiable lexicogrammatical patterns recur, which appear to serve communicative purposes. Previous research has posited that such patterns may serve strategies such as enhancing prominence, increasing explicitness, reinforcing propositions (Dewey 2007), exploiting shared cultural references and economization, and may lead to the preferential use (or, indeed, elision) of particular structures or lexemes, including, for example, the use of redundant items, the regularization of forms and analogy (Seidlhofer 2004; Dewey 2007; Jenkins 2009; Schneider 2012).

To investigate the salient structural characteristics ${ }^{9}$ of street-level commercial signs which appear to be characteristic for this context and domain, the study will include data from contexts characterized by multiplex and uniplex social networks (Milroy 2004); that is, social environments which may be described as more linguistically conservative and norm-enforcing (multiplex social networks), and those in which social relations are more fluid and individually-based (rather than primarily family or tribal-orientated), and the population is likely to be more mobile (uniplex social network).

The analysis of the corpus sought to identity grammatical features which commonly appeared in the corpus on signs from multiple locations. These features appear to have evolved as accepted formulations used to advertise particular goods or services and, as such, were likely more easily processed by prospective clientele. Not a straight-forward case of 'English linguistic hegemony' (Phillipson 1992:73) leading to increased linguistic homogenization within this language community, the use of English at the street level provides evidence of a dynamic hybrid linguistic culture with its own conventions.

\section{The language of signs}

The use of English in advertising, whether in print matter or on commercial signs, has been a rich area of research on language in contact for decades (Piller 2003). Common research foci range from the identification and analysis of words (usually English) used in particular commercial domains (El-Yasin and Mahadin 1996; Ross 1997; Schlick 2002) and calculations of the distribution of particular languages within a domain or advertising sector (McArthur 2000; MacGregor 2003).

Since Landry and Bourhis's (1997) study in particular, studies have viewed the language of public advertising, a contributor to the 'linguistic landscape' 


\section{2 - Louisa Buckingham}

of a geographical area. Accordingly, the distribution of languages in public spaces may be viewed as an indicator of power relations between linguistic or ethnic groups; the choice or combination of languages may index solidarity, prestige, wealth, modernity (Dimova 2008), indicate the linguistic vitality of minorities in particular zones (Cenoz and Gorter 2006; Ling 2013) or levels of literacy in particular languages within a community (Shiohata 2012), or signal political and social change following a period of social conflict (Rosendal 2009; Taylor-Leech 2012).

This study differs from the aforementioned in several ways. First, due to requirements in Oman that commercial signs be bilingual (English/Arabic), the distribution of languages on signs in particular commercial domains or socio-economic or geographic areas is not a useful focus. Second, most studies focused on only one or two cities (or selected suburbs of a city) and thus do not purport to provide a nation-wide coverage. Third, unlike environments where the use of English (or other foreign languages) on commercial signs is used as a strategy to appeal to certain consumer groups or to differentiate the establishment from others (Backhaus 2006; Dimova 2008; Lawrence 2012; Taylor-Leech 2012) without providing a high degree of informational content, in Oman the informational content of commercial signs in English is paramount, as a significant percentage of the establishment's potential clientele cannot read Arabic. The establishment's clientele may not be proficient in English either, however, and is unlikely to understand references to AngloAmerican cultural concepts (for instance, such as those found in aforementioned studies on signs in Hong Kong, Tokyo, Seoul or in Macedonia); this means that that it is in the commercial interests of the proprietor to limit the degree of linguistic license or creativity used for advertising purposes on a sign, that is, to keep language use within certain parameters commonly found within this territory which appear to provide a processing advantage. This is likely to have a regulatory effect on the lexico-grammatical features of English use on signs, as linguistic innovations and uniqueness are less likely to be easily comprehended by such a socially and ethnically diverse clientele.

\section{Data collection}

The corpus for this study was compiled between March 2012 and May 2013. I visited towns and urban centres throughout the country over this period for the purpose of photographing commercial signs. The primary objective was to compile a corpus which represented street-level advertising of different commercial sectors at different locations nationwide. The exclusion of national or international chain stores from this corpus did not undermine the aspiration of this study to provide a nation-wide 'snapshot' of English in commercial signage, as the greater part of Oman's retail and trade sector is in the form of localized small or medium-sized enterprises with fewer than 10 employees. While accurate economic data to support this assertion is not available, 
extensive travel throughout the country over a period of two years and, during the data collection period, surveying on foot the commercial districts of all urban centres visited and questioning employees in selected establishments has provided the author with extensive anecdotal data in support of this. Upon arriving at each location, photographs were taken of signs above establishments on all main streets in the commercial centre and on all connecting side and back streets. As Oman's urban centres are generally relatively small, this usually meant that all streets in the commercial district were included in the data compilation. Due to the size of the capital Muscat, however, two central districts were selected, Ruwi and Mutrah; these very established historical commercial districts are home to an extensive and diverse community of merchants and tradesmen (Peterson 2004; 2007). The peripheral suburb, Seeb, incorporated into Muscat's expanding radius in recent decades (Peterson 2007 : 110), was also included.

The selection of locations for inclusion in the corpus obeyed two imperatives: to include examples of signs from establishments serving communities characterized by weak social ties which would be more likely conform to Milroy's uniplex social network (i.e., either larger urban centres with a high proportion of transient or short to medium term residents or locations on transit routes catering for an ethnically, linguistically and socially diverse mobile clientele), and those serving well-established, more sedentary communities, where Omanis may be more commonly employed in service provider positions and a lower concentration of expatriate workers or transiting populace would be expected. Due to cohesive extended family units and a traditional tribal-based society (Al-Barwani and Albeely 2007), kinship and tribal social networks among Omanis may be extensive; multiplex networks may be especially strong in locations where extended or intermarried families may have lived for generations. These were more likely to constitute towns or villages or city districts removed from the commercial centre.

With this objective in mind, the corpus sought to include the main city of each region as this constituted the economic hub; second, smaller towns in each region, particularly those on main transportation routes as these were often home to trade and retail enterprises providing goods and services to a population transiting the area (i.e., to consumers from other regions); third, villages surrounding these towns serving a small resident population with a limited array of good and services. Table 1 displays the 29 locations included in the corpus, grouped according to administrative districts. The estimated level of social interconnectedness among the populace of each city is indicated by the terms uniplex (U) and multiplex (M) after each name. The estimation was based on the size of the location, the prevalence of expatriate labour on account of industry or commercial activities, and its proximity to roadways frequented by a high volume of transit traffic. The categorization is one of degrees, however, as in most locations both types of social networks may be found, the intensity of each depending on the city district. Also provided in 
Table 1. Data collection locations and total data at each location (8 administrative districts and 29 urban centres)

\begin{tabular}{|c|c|c|c|}
\hline Muscat & Ad-Dakhiliyah & $\begin{array}{l}\text { Ash-Sharqiyah } \\
\text { North }\end{array}$ & $\begin{array}{l}\text { Ash Sharqiyah } \\
\text { South }\end{array}$ \\
\hline $\begin{array}{l}\text { Amarat } \\
\quad\left(\mathrm{U}^{*}, 139^{* *}\right) \\
\text { Mutrah }(\mathrm{U}, 54) \\
\text { Ruwi }(\mathrm{U}, 108) \\
\text { Seeb }(\mathrm{U}, 36) \\
\text { Quiriyat }(\mathrm{U}, 55)\end{array}$ & $\begin{array}{l}\text { Adam (M, 17) } \\
\text { Bahla (M, 63) } \\
\text { Birkat Almouz } \\
\quad(\mathrm{M}, 26) \\
\text { Izki }(\mathrm{M}, 10) \\
\text { Nizwa }(\mathrm{U}, 244) \\
\text { Menah }(\mathrm{M}, 24)\end{array}$ & $\begin{array}{l}\text { Almudaybi } \\
\quad(\mathrm{M}, 12) \\
\text { Ibra }(\mathrm{M}, 63) \\
\text { Maqaniat } \\
\quad(\mathrm{M}, 6) \\
\text { Sinaw }(\mathrm{M}, 45) \\
\text { Wadi Bani } \\
\quad(\mathrm{M}, 15)\end{array}$ & $\begin{array}{l}\text { Alkamil }(\mathrm{U}, 45) \\
\text { Al-Ashakrah } \\
(\mathrm{M}, 39) \\
\text { Sur }(\mathrm{U}, 71)\end{array}$ \\
\hline Al Batinah North & Al-Batinah South & Ad-Dhahirah & Dhofar \\
\hline $\begin{array}{l}\text { Al-Khaburah } \\
\text { (U, 36) } \\
\text { Al-Suwayq } \\
\text { (U, 29) } \\
\text { Saham (U, 27) } \\
\text { Sohar (U, 69) }\end{array}$ & $\begin{array}{l}\text { Barka }(\mathrm{U}, 68) \\
\text { Musanna }(\mathrm{U}, 130)\end{array}$ & $\begin{array}{l}\text { Ibri }(\mathrm{U}, 36) \\
\text { Misken }(\mathrm{M}, 18)\end{array}$ & $\begin{array}{l}\text { Mrbat (M, 12) } \\
\text { Salalah }(\mathrm{U}, 109)\end{array}$ \\
\hline
\end{tabular}

Notes: * $\mathrm{M}=$ multiplex; $\mathrm{U}=$ uniplex; $^{* *}$ Number of signs collected at this location.

Table 1 is the total number of signs collected at each location (indicated in brackets). The disparity between the figures provides an indication of the relative intensity of commercial activity at each location.

The approach taken in the compilation of the corpus was as follows. At smaller or medium-sized locations, all (or virtually all) commercials signs were photographed; in larger cities this was unfeasible and the following method was adhered to. First, where viable, examples from all economic sectors at each location were included; second, examples of signs which were either linguistically typical (i.e., they reflected a form of advertising goods or services frequently seen at this location) or idiosyncratic were documented. All writing appearing in English on the sign was later copied onto an Excel spreadsheet, accompanied by a brief description of location, economic sector or type of goods or services provided, the enterprise name, the translation of certain words into Arabic where necessary, and the identification of salient lexico-grammatical features. The corpus included over 40 different enterprise types (these have been grouped in 16 broad commercial sectors). The categorization can only be approximate, however, as an enterprise would often offer a diverse range of wares or services; thus a company categorized as a property developer might also rent cars. The range of enterprises is displayed in Table 2 and a breakdown of the main commercial sectors by location is provided in Table $3 .^{10}$ 
Table 2. Enterprise types

\begin{tabular}{|c|c|}
\hline Sector & Service or product \\
\hline Food & $\begin{array}{l}\text { groceries and fresh produce (91), meat and/or fish } \\
\text { (97), restaurant and/or fast food (47), bakery } \\
\text { (33), food packing and processing (8), mill (7) }\end{array}$ \\
\hline Personal grooming & $\begin{array}{l}\text { hair dresser (84), beauty parlour (33), cosmetics } \\
\text { (27), perfumes (34) }\end{array}$ \\
\hline Bookshop & books (9), stationery (14), music (5) \\
\hline Clothing & $\begin{array}{l}\text { textiles (35), clothing (48), sports attire (9) } \\
\text { footwear (65), laundry and ironing (26), tailor } \\
\text { (82), wedding accessories (9) }\end{array}$ \\
\hline Jewellery & jeweller (36), smith (10), watches (32) \\
\hline Household goods & $\begin{array}{l}\text { kitchen utensils and appliances (54), furniture (29), } \\
\text { furnishings (44) }\end{array}$ \\
\hline Computers & computer and electronic appliances (50), \\
\hline Construction & $\begin{array}{l}\text { construction (85), building supplies (42), } \\
\text { landscaping (3), machinery (41), pest control (8), } \\
\text { water filters (15) }\end{array}$ \\
\hline Trades & $\begin{array}{l}\text { metal workshops (32), carpentry (22), electrician } \\
\text { (33), plumbing (10) }\end{array}$ \\
\hline Telecommunications & mobile phones (29), satellite dishes (11) \\
\hline Vehicles & $\begin{array}{l}\text { car rental and sale (18), vehicle maintenance (157), } \\
\text { bicycle sale and repairs (14), boat repair (6) }\end{array}$ \\
\hline Health & clinic (4), pharmacy (4), optician (11), gym (1) \\
\hline Agriculture and Animals & agricultural supplies (13), pet shop (11) \\
\hline Business services & $\begin{array}{l}\text { lawyer (5), recruitment (5), cleaning (7), document } \\
\text { brokerage (20), currency exchange (6), road } \\
\text { transportation (13) }\end{array}$ \\
\hline Miscellaneous products & tobacco products (9), gifts (22), weapons (4) \\
\hline Miscellaneous services & $\begin{array}{l}\text { key cutter (8), sign writer (3), photocopying (16), } \\
\text { event organizer (5), real estate (21), travel } \\
\text { agency (6), professional training (6) }\end{array}$ \\
\hline
\end{tabular}

\section{Results}

The different findings from the analysis of this corpus have been grouped as follows: structures used to announce the service, itemize activities, and to specify and describe the product. Within each of the four subsections, specific grammatical features are discussed which were identified as being common to multiple examples in the corpus, and attested at more than one geographical location. For each feature, a selection of examples is provided from the corpus; the city where the sign was photographed is provided in brackets to provide evidence of the widespread nature of the phenomenon discussed. The original spelling and punctuation have been retained. The frequency of each feature in the corpus is indicated in brackets. 
396 - Louisa Buckingham

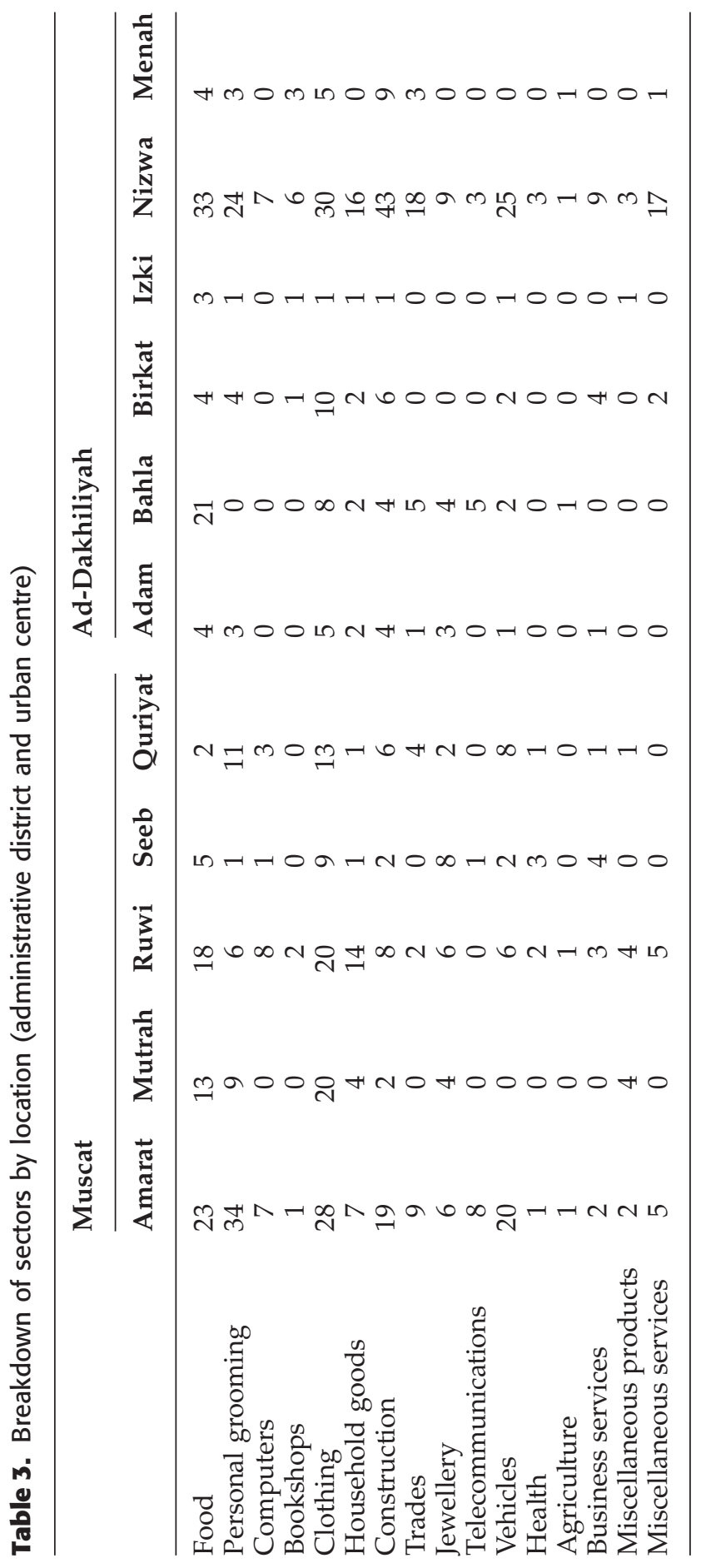

(C) 2014 John Wiley \& Sons Ltd 
Structural features of commercial signs $\mathbf{3 9 7}$

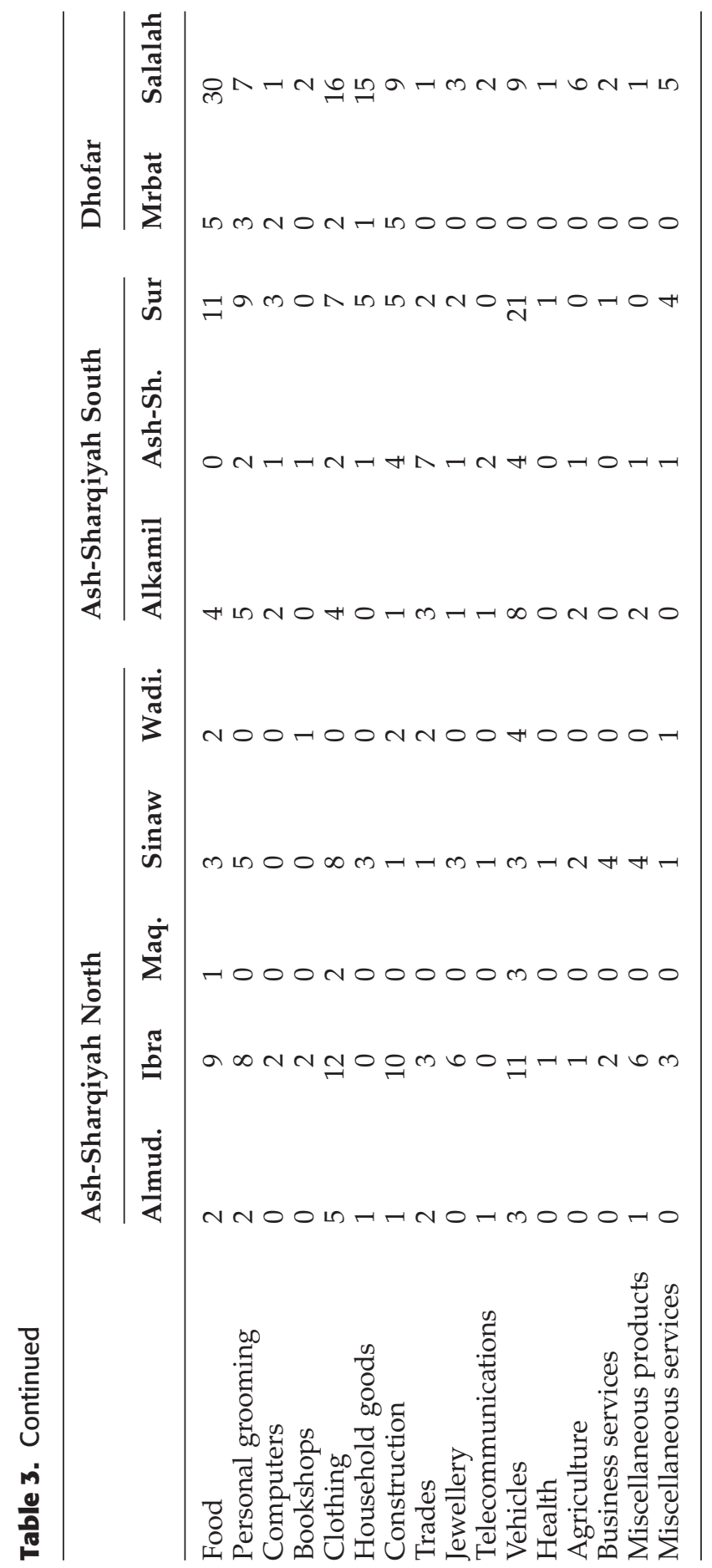

(C) 2014 John Wiley \& Sons Ltd 


\section{Louisa Buckingham}

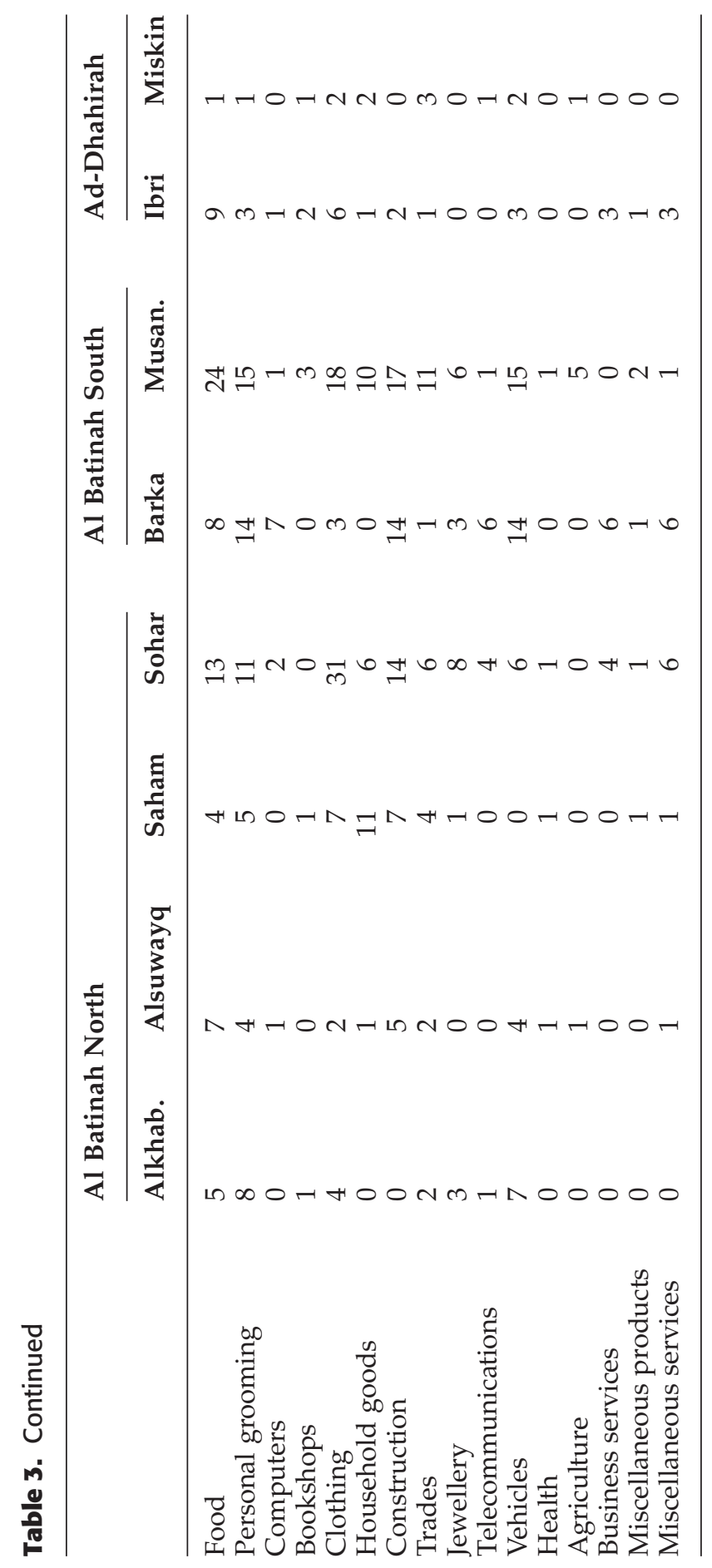

(C) 2014 John Wiley \& Sons Ltd 


\section{Structures used to announce the service}

\section{The noun phrase}

A very common approach to announcing the type of ware or service offered by a particular store is to begin with a nominalized transaction verb: 'sale of' (249), 'sales of' (5) or 'retail of' (70); 'wholesale of' (18); 'trade of' (15). These nouns also appear as a verb or gerund, for example, 'sell' (3) or 'selling' (13). While announcing the enterprise as a retailer might be viewed as semantically redundant (extralinguistic contextual information fulfilled this purpose), the performative move served the objective of enhancing prominence.

(1) Sale of fresh \& frozen chicken sale (Sinaw)

(2) Sell of fodder, seeds, fertilizers, insecticides (Alsuwayq)

(3) Selling of foods (Sinaw)

(4) Retail of bakery products (Musanna)

(5) Trading of meat \& slaughtering of chicken (Salalah)

The inclusion of the noun was most common where additional activities were also undertaken by the enterprise (see Figure 1); these were also listed (sometimes resulting in the repetition of 'sale', or the simultaneous inclusion of 'sale', 'retail' and 'wholesale'; see examples 9 and 10). 'Sale' was often the first element of a complex noun phrase with two co-ordinated noun phrases, beginning with 'Sale \&' or 'Sale and' (76 examples in total). In addition to the parallel structure comprising two coordinated nouns usual in standard English dialects, ${ }^{11}$ in the position of the second noun a verb may appear or an alternative nominalized form, for example, the gerund used as a noun. The example 'sale \& repairing' was particularly common (30 examples, compared with 8 occurrences of 'sale \& repair').

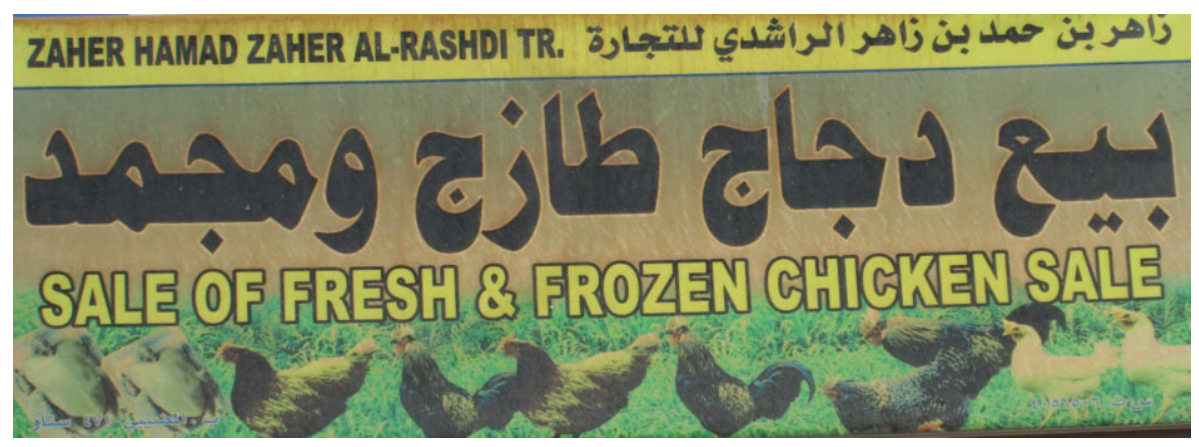

Figure 1. The noun phrase

(c) 2014 John Wiley \& Sons Ltd 
(6) Sale \& repairing of electronic devices \& broadcasting of satellite (Bahla)

(7) Sale and fixing water sanitating machines, cleaning contracts pestisites (Ibra)

(8) Sell \& maintaine desktops \& laptops, their accessories \& network devices (Nizwa)

(9) Retail of footware, retail of bags, wholesale of perfumes, cosmetics, gifts \& novelties, retail of sovenirs, paintings \& gifts (Amarat)

(10) Wholesale of household furniture, retail of rugs, carpet \& manufacture of curtains (Musanna)

Signs also commonly begin with a prepositional phrase headed by 'For' (76 examples in the corpus), a structure common in Arabic. The preposition may be followed by a gerund verb or a noun.

(11) For repairing and selling phones (Bahla)

(12) For making and packing dates (Bahla)

(13) For arranging tourist programme (Brkat Almouz)

(14) For wedding accessories and dresses rent (Ibri)

(15) For tents \& function article rent (Musanna)

(16) For making \& sale Omani Halwa (Nizwa)

Nominalized transaction verbs may appear at the end of a, sometimes lengthy, compound noun -phrase. The words 'sale' (112), or 'rent(al)' (14) appear for goods, while 'work(s)' (47), 'repair' (44), 'service(s)' (33), 'fitting' (12) or 'fixing' (4) are used if a service is advertised. This appears to be a more concise way to list services and avoid a prepositional phrase (e.g. 'sale of').

(17) Car oil changing \& sale (Sohar)

(18) Tailoring (gents) \& clothes sale (Nizwa)

(19) Foods, fruits \& vegitable sales (Bahla)

(20) Engine \& machine equipments sale (Sur)

(21) Shoe stitch \& sale (Ruwi)

(22) Water purification machines sale (Salalah)

Further analysis of the corpus reveals that the post-position of the gerund is very common (examples 23 to 29). The corpus contains 247 examples of the gerund in this position. As Arabic is a VSO language, this structure does not appear to reflect the influence of Arabic; it might however be testimony to the influence of Hindi, which is usually described as a SOV language.

(23) Gold \& silver smithing (Nizwa)

(24) Ladies cloths tailoring (Nizwa)

(25) Electronic rep. \& dish fixing (Bahla)

(26) Cloth ironing (Ruwi) 
(27) Cartridges refilling (Ruwi)

(28) Water wells drilling (Musanna)

(29) Keys duplicating (Sur)

\section{Structures used to itemize activities}

Multiple verbs

Multiple verbs may appear on one sign to express the range of activities undertaken by the establishment. The corpus contains 103 examples of signs containing three or more verbs, (a mixture of simple, nominalized and gerund forms), and 58 examples of signs with just multiple gerunds. Typically, the effect is a list of services provided (examples 30 to 33); alternatively, the use of multiple verbs enables the 'unpacking' of the activity. In examples 34 and 35, in place of using superordinate terms 'mechanic' or 'real estate agent', sub-activities are concretized, or 'unpacked'. This tendency occurs across a range of commercial sectors.

(30) Exporting \& importing goods loading (Nizwa)

(31) Building cont., land transporting, payment water bill, water \& electric laying (Menah)

(32) Print smart forms, the completion and clearance of transactions, photocopy (Birkat Almouz)

(33) Building cont., complete transactions, clearance, bring labour, well digging, management of petrol stations (Nizwa)

(34) Repairing \& cleaning motor vehicle radiators, motor vehicle repair \& recharging of batteries (Quriyat)

(35) Buying, selling \& subdividing real estate (Sohar)

The 'unpacking' of an activity into its components is particularly common in the case of male grooming (see Figure 2). Not only are beards

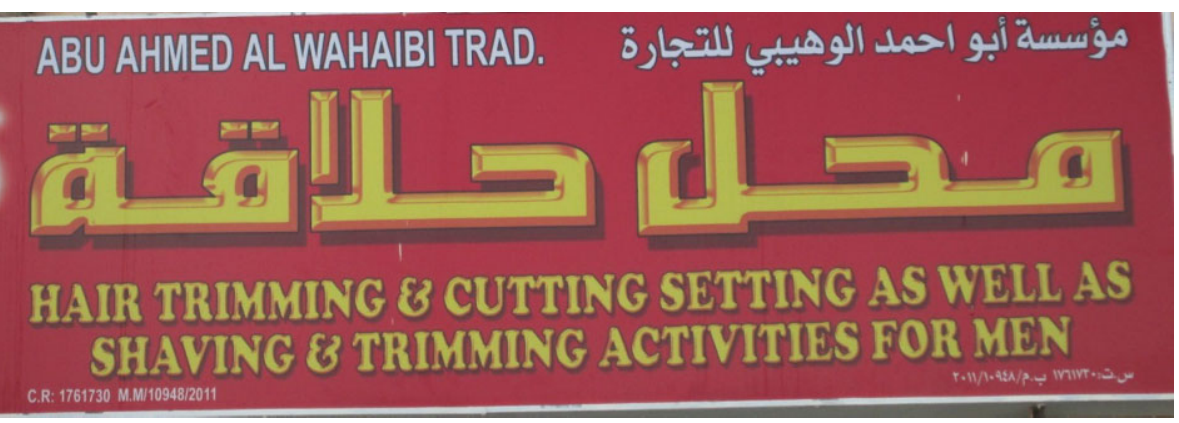

Figure 2. Itemizing activities with the gerund

(c) 2014 John Wiley \& Sons Ltd 


\section{Louisa Buckingham}

or moustaches common, but local fashion among young males in particular is to maintain facial hair immaculately clipped and styled. This creates a demand for barbers; hence the relatively high number of signs from such establishments in this corpus. The following examples illustrate the tendency to 'unpack' the general hair grooming activity into discrete components from around the country. (The corpus contains 16 examples of this type.)

(36) Hair trimming \& cutting, setting for men (Saham)

(37) Shaving \& beard trimming activities for men (Alsuwayq)

(38) Hair cutting, trimming shaving \& beard trimming for men (Amarat)

(39) Hair trimming \& cutting setting as well as shaving \& trimming activities for men (Ruwi)

\section{Structures used to specify the product}

Article use

Article use is infrequent on commercial signs, as the noun reference in this genre tends to be of a general rather than specific nature. The overwhelming majority of the several thousand nouns contained in the corpus occurred without an article. Of the 45 instances of article usage (36 definite, nine indefinite), 28 may be judged as differing from standard dialect usage (examples 40 to 45). One might conclude that within this particular text type in Oman, the overextension of article use is not a salient feature. This finding contrasts with suggestions by Dewey (2007) and Seidlhofer (2004) that an overextension of the use of the definite article to give greater salience to particular nouns may be quite common in contexts in which English is used as a lingua franca.

(40) For organization the exhibition (Barka)

(41) Building cont, equipment rental, export, import, cleaning \& fighting the insect (Birkat Almouz)

(42) The tailoring apparatus sale (Saham)

(43) Trading the sanitary ware (Ibra)

(44) Restaurant \& the wedding (Misken)

(45) An oven bakery (Alsuwayq)

The genitive structure and possessive adjectives

A clear example of Arabic influence in the use of English on signs is the structure of compound nouns. The genitive may be used with inanimate nouns, when in standard British/US dialects a compound noun or 


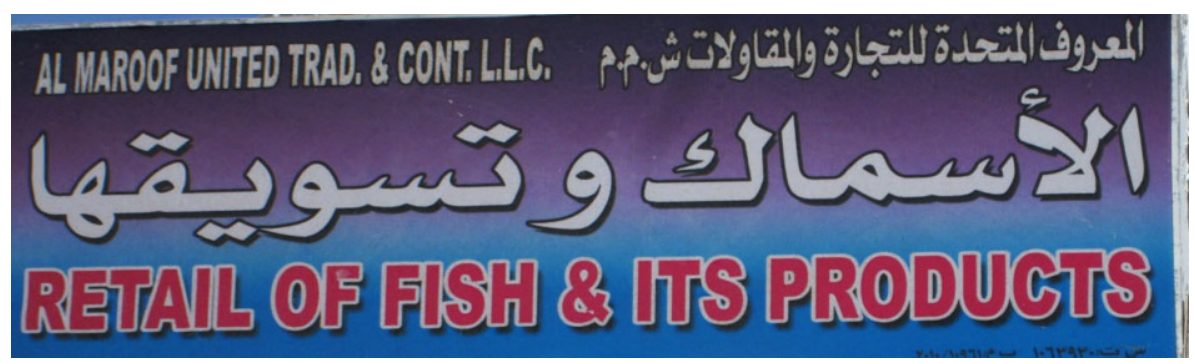

Figure 3. Possessive Adjective

prepositional phrase would be expected (e.g. car rental; sale of sanitary wares). The corpus contains 38 examples of the genitive structure. (The apostrophe to signal the genitive structure may appear.)

(46) Sale of motorcycle's spare parts (Nizwa)

(47) Market's center for shopping (Sinaw)

(48) Car's rent, rent a tent (Birkat Almouz)

(49) Repairing of tyres puncture (Alkamil)

(50) Sale of fresh cold meat and fishes products (Salalah)

(51) Repair of car's radiator and silencer (Barka)

The possessive pronoun may be inserted where a determiner would be unnecessary in standard English dialects. This is evidence of the influence of Arabic, which would require a possessive pronoun in such instances (see Figure 3). This feature does not appear to be in expansion, however, as the corpus contains only nine examples of this. The two most common nouns in this construction, 'products' and 'accessories', appear more frequently without the possessive pronoun as 'and products' (8) or 'and accessories' (14).

(52) Retail of fish and its products (Ruwi)

(53) Retail of pets and their accessories (Salalah)

(54) Wedding dress \& their requirements for rent (Sohar)

(55) Repair tires, oil changes \& their derivities (Sur)

(56) Natural herbs \& their derivatives (Sohar)

\section{Uncountable nouns}

A contrasting tendency of leaving the noun undefined (without a determiner), and employing a plural morpheme with (in standard British/US dialects) usually uncountable nouns is a regular feature on signs throughout the 


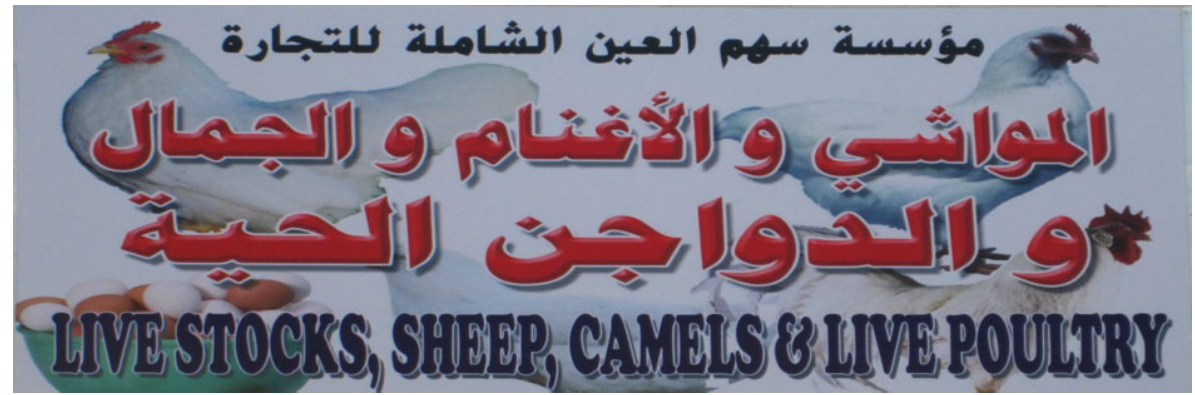

Figure 4. Plural uncountable nouns

country. The following list demonstrates the relative frequency of some plural forms (the first number refers to the plural form and the second to the singular form of each word found in the corpus): equipments $(47 / 43)$; feeds (5/3); fishes (4/31); foods (9/19); footwares (1/13); fruits $(15 / 2)$; furnitures $(5 / 28)$; granites $(4 / 1)$; jewelleries $(2 / 28)$; livestocks $(2 / 0)$; marbles $(5 / 2)$; meats $(4 / 46)$; oils $(5 / 15)$; travels $(4 / 1)$; papers $(1 / 0)$; researches $(1 / 0)$; wears (1/4); and works (42/17).

Although this corpus does not pretend to be exhaustive and it is thus not possible to determine categorically whether some nouns are more common in the plural or the singular form in shop advertising, nouns such as 'works', 'equipment' and 'fruit' are not only frequent in the corpus, but are also particularly frequent in the plural form. A process of analogy may be the motivating factor, as collective nouns such as 'items', 'wares', 'articles' and 'vegetables' appear commonly on signs in the plural. Analogously, 'works' is likely used as an extension of the pattern seen in the same context of other collective nouns such as 'activities' and 'services'. The word 'ware', when used as a morpheme in software, was found once in the plural ('softwares'); it was also found in plural in cases where the word 'wear' appears to be reanalysed as 'ware', resulting in 'footwares' and 'scout wares'. Not all uncountable nouns are subject to this, however, many common uncountable nouns (e.g. food, oil, furniture) appear more frequently in the singular. During the data collection period, no instances were sighted of nouns such as 'sheep' or 'poultry' with a plural morpheme; as they usually appeared on signs together with plural nouns, they might have been assigned a plural morpheme by analogy (see Figure 4).

(57) For kitchen \& marbles (Salalah)

(58) Sewing \& repairing footwares (Sur)

(59) Softwares \& computer accessories (Quriyat)

(60) Translation and typing services school \& university researches (Ibra)

(61) For gold \& jewelleries (Salalah)

(62) House equipments sale (Sur) 


\section{Structures used to describe the product}

\section{Noun modification}

Further evidence of the influence of Arabic is the word order within the noun phrase; adjectival post-modification of the noun (usual in Arabic) occurs primarily (but not exclusively) in the meat retail sector (see Figure 5). In this cultural context, the condition of the meat (cold, frozen, freshly slaughtered) is an important attribute of the product and multiple adjectives may be used. The following adjectives appeared with meat and fish (the first figure represents the total number in the corpus, the second figure represents the instances of post-modification): fresh $(29 / 0)$, cold $(6 / 2)$, frozen $(23 / 3)$, slaughtered (6/3), live $(3 / 1)$, freezing $(2 / 2)$, murdered $(1 / 1)$. Nevertheless, the vast majority of noun phrases with adjectival modification displayed the $\mathrm{ADJ}+\mathrm{N}$ structure. For instance, the most common adjectives in this corpus, ready/readymade (30), fresh (31), manual (24), and artificial (16), never appeared as post-modifiers. Thus, it does not appear that the N+ADJ structure is in expansion and it seems unlikely to endure.

(63) Meat \& poultry products slaughtered sale (Sohar)

(64) Sale of fresh meat cold freezing (Alkamil)

(65) Sale of fresh meat, frozen \& fish production (Amarat)

(66) Sale of chicken fresh \& frozen (Ibra)

(67) Age young fashion center (Nizwa)

In plural noun phrases with adjectival modification, the adjective, together with the noun, may carry the plural morpheme. The use of 'electronics' with

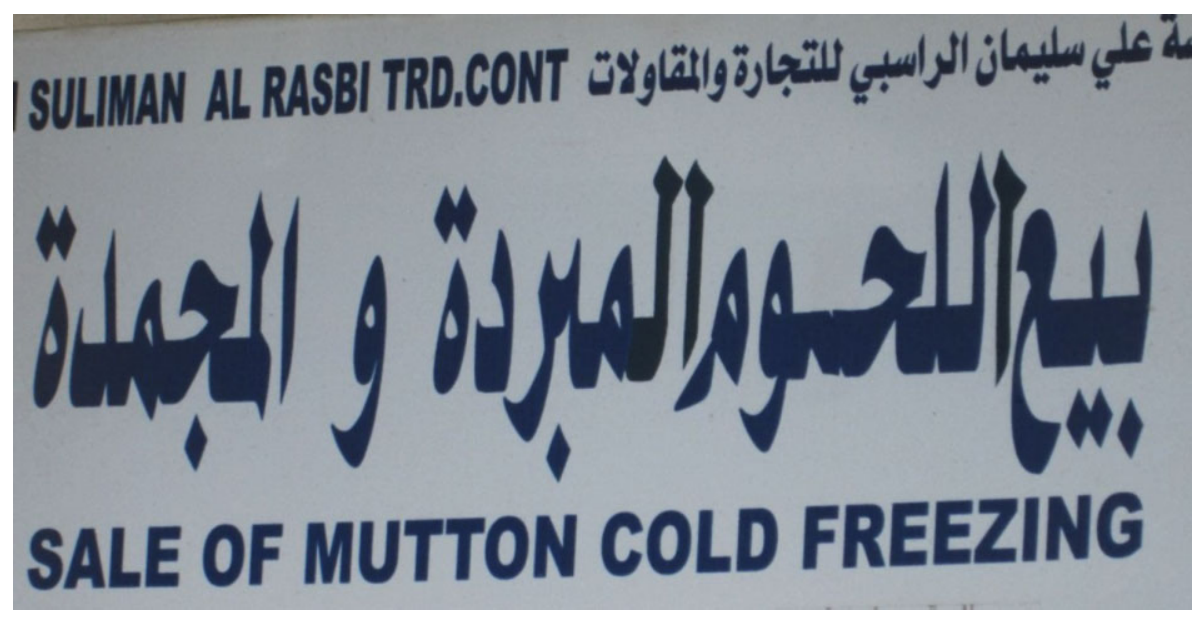

Figure 5. Adjectival post-modifier

(C) 2014 John Wiley \& Sons Ltd 


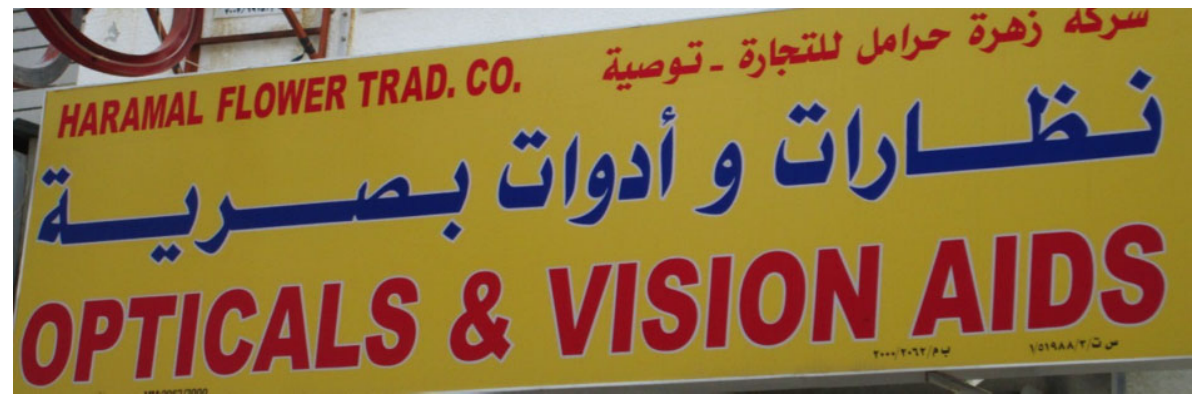

Figure 6. Change of word class

a plural noun (e.g. electronics equipments) is common; of the 29 occurrences of 'electronics', 19 are of this type. Although this may be due to influence from Arabic where adjectives are marked for gender and number, this feature is not found with other adjectives. Alternatively, it may be the result of a reanalysis of the word 'electronics', which has become to be used as a noun.

(68) Electronics goods repairing (Bahla)

(69) Sale \& repairing of electronics items (Musanna)

Certain adjectives (or noun modifiers) may become the nucleus of the noun phrase upon the elision of the noun (see Figure 6). These adjectives thus appear as nouns (usually in the plural form). Examples in the corpus involve the following adjectives (the first figure refers to the number of times the adjective appears, and the second figure is the number of times it appears alone as the nucleus of a noun phrase): 'imitation' (11/3), 'imitations' (2/2), 'optical' (3/1), 'opticals' (7/7), 'miscellaneous' (4/1), 'sitting' (3/3), 'household' (29/2), 'households' (3/3), 'electrical' (51/8), 'electricals' (5/5), 'mechanicals' (1/1), 'readymade' (34/8), 'readymades' (6/6). Not all adjectives are subject to this, however; in 'artificial jewellery', widely used as a synonym for 'imitation jewellery', the adjective was not found with a plural morpheme. The process whereby the adjective undergoes a change of word class appears to lead to semantic narrowing; namely, the word assumes a specific meaning within this context: imitation (imitation jewellery), opticals (glasses); readymade (clothes), household (kitchen utensils), sitting (sitting room furniture). A variation involves the shift of the modifier in a complex noun phrase consisting of two nouns to the nucleus position: 'sanitary wares' becomes simply 'sanitary' (22/4) or 'sanitaries' (1/1); in example 71, 'bedrooms' is an abbreviation of 'bedroom furniture'.

(70) Watches \& imitations sale \& repair (Sohar)

(71) Bed rooms, arabic sitting, carpet, curtains, office furniture (Musanna)

(72) Building contracting, extending water \& electrical (Saham) 
(73) Readymades \& textiles (Salalah)

(74) Retail of toys, games, footware, miscellaneous, household utensils, perfumes, toilet soap, bakhur (Amarat)

(75) Households, electronic \& electric appliances (Ruwi)

\section{Discussion}

The frequency and widespread use of selected examples nation-wide evidenced in this study indicate that certain linguistic forms appear to be accepted as favoured formulations within the domain of street-level advertising, potentially indicating the incipient nativization of these forms (Schneider 2003) in this communicative context.

Bamgbose (1998) recommends consideration to five factors in determining the extent to which localized variants may be considered durable innovations: demographic and geographic spread, level of acceptance, authoritative use and codification. While codification, representing the final phase in Schneider's dynamic model of English, would be premature in the case of English in GCC countries (Boyle 2011), other conditions for considering some variants discussed in this study as innovations apply. Many of the examples are attested nation-wide in locations where social relations may be characterised as uniplex and multiplex (Milroy 2004) and are used by both the indigenous and expatriate communities. An indication of the level of acceptance of certain forms discussed here in domains with higher social prestige than street-level, small-scale business advertising can be seen in their use in Omani government websites. On Oman's Ministry of Manpower website, $^{12}$ the use of gerund and the final position of the verb can be found (e.g. 'used cars selling'), reflecting patterns identified in this corpus.

Certain linguistic structures in lingua franca contexts may serve the objective of enhancing prominence. This was found in the form of performative moves to announce the function of the establishment; thus, beginning with a complex noun phrase such as 'sale of' or 'retail of'. Alternatively, the promotional move may begin with the preposition 'for' (e.g. 'For barber \& beauty'), a structure that, due to the Arabic influence, appears to have become idiomatic, or nativized, in Oman within the context of this text type.

The enumeration of discrete activities, typically achieved by multiple verbs, appears to serve the goal of increased explicitness. The itemization of activities (where distinct services are listed) or the unpacking of an activity (where an activity is broken down into discrete components), appears particularly common in the domains of curtain making, hair dressing, landscaping, or car maintenance. The effect of emphasizing the performance of actions would not necessarily be achieved by abstractions such as 'mechanic'. This rhetorical structure likely represents a culturally embedded modification (Richards 1979) which appears to function effectively within the 
context of street-level commercial advertising. Lowenberg (1986: 7) refers to such rhetorical variations as instances of English being "equipped to function effectively in non-Western, multilingual speech communities" and underscores that the provision of such detail may represent an appropriate discursive style within some South Asian cultural contexts.

The transfer of features from languages in the local environment into English is a further commonly noted characteristic of nativization processes (Lowenberg 1986; Schneider 2003). The use of the genitive structure with inanimate nouns (e.g. 'Car's rent') reveals the influence of the substrate language Arabic and confirms a pattern identified in Boyle's (2011) investigation of the English of newspaper texts in the UAE. As this feature has been found to be salient in a distinct, authoritative genre in a neighbouring GCC country and appears with reasonable frequency in this corpus, it may endure. The influence of Arabic is also found in the use of the possessive adjective ('Retail of fish and its products'), thereby creating an explicit anaphoric reference between the two nouns which would be unusual in standard English dialects. In the product description on signs, adjectival postmodification (typical in Arabic) is found particularly when describing meat (e.g. 'Mutton frozen'). It is possible that the cultural relevance of this adjectival modification (e.g. frozen, fresh, chilled, etc.) within this local context triggers the Arabic influence in English. Only very limited numbers of the latter two features were found in this corpus and, despite being found at different locations, their limited use would make them unlikely candidates for indigenization, according to Bamgbose's (1998) criteria.

Structural influence from Hindi, where SOV order is usual, is perhaps found in the frequency with which a verb occurs at the end of a noun phrase. This post-position extends beyond transaction verbs (such as 'sale', 'rent', retail'), to potentially all verbs describing the service advertised. In some cases, this would be in alignment with British/US standard dialects ('Car polishing'; 'Bicycle sale'), but in many cases this appears to be a localized norm in Oman (and possibly in other GCC countries), particularly when the gerund is used ('Water well drilling'; 'Cloth ironing'; 'Goods loading').

A further feature of language use on signs in Oman is the flexibility of word class in the case of particular words. Selected adjectives may become the nucleus of a noun phrase and, as such, may carry the plural morpheme ('Watches \& imitations sale'); it appears to be a form of economizing through elision. As the meaning is transferred to the adjective, the elision of the noun does not entail semantic loss. Within this text type, only a limited range of adjectives undergo word class conversion; in the case of 'electronics', 'imitation', 'opticals' and 'readymade', this form is attested nation-wide, in diverse commercial sectors and appears established. As attributes are infrequent on shop signs, however, it is not possible to ascertain whether this tendency is in expansion, or whether it is limited to the examples identified here. Nevertheless, the same economizing process is found (albeit less 
frequently) in the case of complex noun phrases (e.g. 'sanitary wares'); the modifying noun may become the nucleus upon the elision of the original nucleus (e.g. 'sanitary').

The process of analogy, whereby perceived irregularities become 'regularized', appears to operate in the case of the pluralization of some nouns traditionally considered uncountable. As discussed in previous studies (Boyle 2011; Jenkins 2009), the classification of nouns as countable and uncountable may not be an important distinction in lingua franca or world English contexts. In this corpus, selected nouns of this type are frequently perceived as countable. In some cases, this may be motivated by an emphasis on the availability of different types of product ('meats', 'fruits', 'fishes', 'foods'), while in other cases the pluralization may be influenced by the common usage in plural of a synonym in similar contexts (e.g. 'equipments' / 'tools'; ' works' / 'activities').

\section{Conclusion}

The data from this corpus of over 1,600 signs photographed in 29 urban centres throughout Oman has revealed how certain formulations have become, to varying degrees, established in the context of advertising an establishment's products or services at street level. This empirical study builds on Boyle's (2011) investigation into ELF dialectal variants in Emirati media by providing further evidence from a different genre of localized preferences for certain linguistic structures. The grammatical features identified in this study display evidence of how structures may be adapted to give prominence and boost explicitness and economise language use in a cultural context where English is used as a lingua franca between speakers of greatly varying degrees of English competence. The incorporation of structures or rhetorical devices from locally-used languages is evidence of linguistic resourcefulness which, when employed consciously, may translate into an astute marketing strategy in a context where a multi-ethnic, multilingual clientele is assumed.

The narrow specificity of the linguistic domain focused on in this study precludes an extension of these findings to other domains of English language use in Oman. Research across different domains is needed to appreciate more fully the characteristics of English language use in GCC countries and to ascertain the extent to which particular formulations or structures are undergoing a process of nativization. Further, replication studies would enable the integration of a diachronic perspective into research on language contact in the region. In the absence of a comparable record of Oman's linguistic landscape in the past, it is impossible to gauge the length of time current linguistic features of this text type have been in circulation. One can only speculate on the evolution of Oman's linguistic landscape in coming decades. 


\section{0 - Louisa Buckingham}

\section{Acknowledgements}

The support and encouragement of Joseph Rega and Abraham Paniveli made this study possible. I thank Mohammed Qudah, Amira Almaawali and Huda Habsi for their assistance with the Arabic versions on signs and for inquiring into official sign writing procedures. Finally, I thank anonymous reviewers for their constructive comments.

\section{Notes}

1. A political and economic association comprising six states: Saudi Arabia, Kuwait, Bahrain, Qatar, the United Arab Emirates and Oman.

2. The main countries of origin of expatriate workers are (in order of importance): India, Bangladesh, Pakistan, Sri Lanka and Egypt (Kapiszewski 2006).

3. The Ministry of Regional Municipalities in each region is responsible for approving the English and Arabic wording of proposed commercial signs before they are submitted to a sign-writer (personal communication, Huda Al-Habsi, Nizwa College of Applied Science, with information from the Ministry of Regional Municipalities).

4. An example of this discrepancy can be seen in Figures 1 and 2; in Figure 1 the Arabic version does not include a redundant repetition of 'sale'. In Figure 2, the English version contains a detailed description of services; the Arabic version says simply 'Barber shop' (Mahal hilaqah).

5. In Oman, enterprises with multiple branch offices or outlets are mainly limited to chain stores such as Lulu, Carrefour, selected restaurants, petrol stations and new car dealers.

6. The five stages of Schneider's model are: foundation, exonormative stabilization, nativization, endonormative stabilization, differentiation. While stage 2 is found in the strong EFL orientation in educational contexts, this study proposes that certain lexicogrammatical features appear to be undergoing nativization (stage 3) within the domain of street-level commercial advertising. There is insufficient evidence available to apply the fourth stage, endonormative stabilization, to the Omani context; this involves the emergence of certain distinctive linguistic norms, which would be considered acceptable in formal contexts. As no study has been conducted to date on the use of English in formal contexts in Oman, there is no evidence available to suggest that this stage is applicable to the Omani context.

7. In Oman, British presence has ensured the political integrity of the country during periods such as the Dhofar rebellion (1962-1976), the early development of the national petroleum company, and during the instatement of the current Sultan (Heard-Bey 2002; Louis 2003).

8. British or US standard dialects are used as reference models in imported didactic materials and for language competency evaluations. Scores from TOEFL or IELTS are commonly used as evidence for language competency for university entrance and graduation requirements.

9. Lexical features will be analysed in a separate paper.

10. The total number of examples identified for commercial sectors exceeds the total number of signs; as previously mentioned, a single sign may advertise goods or 
services from multiple commercial sectors (e.g. 'Computer checking and repair of vehicles' in Barka).

11. The notion of standard British or US English used here reflects the dialect found in widely used, authoritative reference works emanating from these countries.

12. Oman's Ministry of Manpower. Accessed 1 September 2013: https://www. manpower.gov.om/en/sanad_forbidden_occupation.asp. The text comprising the list of occupations 'forbidden' for expatriate workers includes multiple examples of the post-position of the gerund: 'Foodstuff selling, mobile phones selling and maintenance, readymade garments and cosmetics selling, fabrics and textiles selling, flowers selling, photography, used cars selling, car wash and oil change outlets, vegetable and fruits selling, fish, meat and poultry selling, ladies beauty saloons [sic], small boats maintenance workshops, cooling equipment selling and maintenance, electrical and electronic appliances selling and supply, tailoring, internet cafes'.

\section{References}

Al-Barwani, A. T. and T. S. Albeely (2007) The Omani family. Marriage E Family Review 41.1-2: 119-142.

Al-Naqeeb, K. H. (1990) Society and state in the Gulf and Arab Peninsula: a different perspective. London: Routledge.

Backhaus, P. (2006) Multilingualism in Tokyo: a look into the linguistic landscape. International Journal of Multilingualism, 3.1: 52-66.

Bamgbose, A. (1998) Torn between the norms: innovations in World Englishes. World Englishes 17.1: 1-14.

Boyle, R. (2011) Patterns of change in English as a lingua franca in the UAE. International Journal of Applied Linguistics 21.2: 143-161.

- (2012) Language contact in the United Arab Emirates. World Englishes, 31.3: 312330.

Bruthiaux, P. (2003) Squaring the circles: issues in modeling English worldwide. International Journal of Applied Linguistics 13.2: 159-177.

Canagarajah, S. (1999) Resisting linguistic imperialism in English teaching. Oxford: Oxford University Press.

Cenoz, J. and D. Gorter (2006) Linguistic Landscape and minority languages. International Journal of Multilingualism 3.1: 67-80.

Dewey, M. (2007) English as a lingua franca: an interconnected perspective. International Journal of Applied Linguistics 17.3: 332-354.

Dimova, S. (2008) English in Macedonian commercial nomenclature. World Englishes 27.1: 83-100.

EIU (2013) Oman: country report. London: Economic Intelligence Unit.

El-Yasin, M. K. and R. S. Mahadin (1996) On the pragmatics of shop signs in Jordan. Journal of Pragmatics 26.3: 407-416.

Heard-Bey, Frauke (2002) The Gulf in the 20th century. Asian Affairs 33.1: 3-17.

Holes, C. D. (2011) Language and identity in the Arabian Gulf. Journal of Arabian Studies: Arabia, the Gulf, and the Red Sea. 1.2: 129-145.

Jenkins, J. (2009) English as a Lingua Franca: interpretations and attitudes. World Englishes 28.2: 200-207.

(C) 2014 John Wiley \& Sons Ltd 


\section{2 - Louisa Buckingham}

Kachru, B. B. (1985) Standards, codification and sociolinguistic realism: the English language in the outer circle. In Randolph Quirk \& Henry G. Widdowson (eds.), English in the world: teaching and learning the language and literatures. Cambridge: Cambridge University Press. 11-30.

Kapiszewski, A. (2006) Arab versus Asian migrant workers in the GCC countries. United Nations Expert Group Meeting on International Migration and Development in the Arab Region, 15-17 May, Beirut.

Landry, R. and R. Bourhis (1997) Linguistic landscape and ethnolinguistic vitality: an empirical study. Journal of Language and Social Psychology 16.1: 23-49.

Lawrence, B. C. (2012) The Korean English linguistic landscape. World Englishes 31.1: 70-92.

Ling, L. M. (2013) The linguistic landscape of Hong Kong after the change of sovereignty. International Journal of Multilingualism 10.3: 251-272.

Louis, R. (2003) The British withdrawal from the Gulf, 1967-71. The Journal of Imperial and Commonwealth History 31.1: 83-108.

Lowenberg, P. H. (1986) Non-native varieties of English: nativization, norms, and implications. Studies in Second Language Acquisition 8.1: 1-18.

MacGregor, L. (2003) The language of shop signs in Tokyo. English Today 19.1: 18-23.

McArthur, T. (2000) Interanto: The global language of signs. English Today 16.1: 33-43.

Milroy, L. (2004) Social networks. In Jack K. Chambers, Peter Trudgill and Natalie Schilling-Estes (eds.), The handbook of language variation and change. Oxford: Blackwell. 549-572.

Park, J. S.-Y. and L. Wee (2009) The three circles redux: a market-theoretic perspective on World Englishes. Applied Linguistics 30.3: 389-406.

Pennycook, A.(2003) Global Englishes, rip slyme and performativity. Journal of Sociolinguistics 7.4: 513-533.

Peterson, J. E. (2004) Oman's diverse society: Northern Oman. Middle East Journal 58.1: 32-51.

- (2007) Historical Muscat. Leiden: Brill.

Phillipson, R. (1992) Linguistic imperialism. Oxford: Oxford University Press.

Piller, I. (2003) Advertising as a site of language contact. Annual Review of Applied Linguistics 23: 170-183.

Richards, J. (1979) Rhetorical and communicative styles in the new varieties of English. Language Learning 29.1: 1-25.

Rosendal, T. (2009) Linguistic markets in Rwanda: language use in advertisements and on signs. Journal of Multilingual and Multicultural Development 30.1: 19-39.

Ross, N. J. (1997) Signs of international English. English Today 13.1: 29-33.

Schneider, E. W. (2003) The dynamics of New Englishes: from identity construction to dialect birth. Language 79.2: 233-281.

- (2007) Postcolonial English: varieties around the world. Cambridge: Cambridge University Press.

- (2012) Exploring the interface between World Englishes and second language acquisition and implications for English as a lingua franca. Journal of English as a Lingua Franca 1.1: 57-91.

Seidlhofer, B. (2004) Research perspectives on teaching English as a lingua franca. Annual Review of Applied Linguistics 24: 209-239.

Shiohata, M. (2012) Language use along the urban street in Senegal: perspectives from proprietors of commercial signs. Journal of Multilingual and Multicultural Development 33.3: 269-285. 
Schlick, M. (2002) The English of shop signs in Europe. English Today 7.1: 3-7.

Taylor-Leech, Kerry Jane (2012) Language choice as an index of identity: linguistic landscape in Dili, Timor-Leste. International Journal of Multilingualism 9.1: 15-34.

Valeri, M. (2007) Nation-building and communities in Oman since 1970: the Swahilispeaking Omani in search of identity. African Affairs 106.424: 479-496.

Willoughby, J. (2006) Ambivalent anxieties of the South Asian-Gulf Arab labor exchange. In John W. Fox, Nada Mourtada-Sabbah and Mohammed al-Mutawa (eds.), Globalization and the Gulf. London: Routledge. 223-243.

Yano, Y. (2001) World Englishes in 2000 and beyond. World Englishes 20.2: 119-131.

email: bucklj@gmail.com

[Received 7 June 2014] 